\title{
Correlation Between Hand Ischemia Questionnaire and Peak Systolic Velocity of Radial Artery and UInar Artery in Hemodialysis Patients with Upper Arm Native Fistula Arteriovenosa \\ Billy Stephanus Karundeng ${ }^{{ }^{*},}$ Akhmadu Muradib ${ }^{b}$ Aria Kekalih ${ }^{c}$
}

Introduction: Steal syndrome that occurs due to vascular access is one of the most feared complications after making a fistula arteriovenous (FAV). It is necessary to develop an assessment for early detection. Hand ischemia questionnaire (HIQ) and measurement of peak systolic velocity (PSV) of the radial artery and the ulnar artery are a form of subjective and objective examinations used to detect steal syndrome. The aim is to determine the correlation between HIQ and PSV of the radial artery and ulnar artery in hemodialysis patients with upper arm's native FAV to detect symptoms of steal syndrome.

Method: This is a cross-sectional study conducted in Cipto Mangunkusumo National Hospital from March to May 2019. Patients undergoing hemodialysis using upper arm native access FAV with or without symptoms of ischemia in the hands were included. Patients were asked to fill HIQ by interview, and then continued with measurement of PSV of the radial arteries and distal ulnar arteries from the hands with FAV.

Results: A total of 80 samples were taken with 43 were women (53.8\%), and 37 were men (46.2\%). About $91.2 \%$ of the samples were FAV at the brachiocephalic level. The median age of the samples was 53 years. From the total HIQ score obtained, the results were a minimum of 0 , maximum of 70 , and a median value of 3 . PSV of radial artery were minimum of $20 \mathrm{~cm} / \mathrm{s}$, maximum of $79 \mathrm{~cm} / \mathrm{s}$, and median $40 \mathrm{~cm} / \mathrm{s}$. The minimum PSV of the ulnar artery was $16 \mathrm{~cm} / \mathrm{s}$, the maximum was $70 \mathrm{~cm} / \mathrm{s}$, and the median was $41 \mathrm{~cm} / \mathrm{s}$. There was a significant correlation between the hand ischemia questionnaire and the peak systolic velocity of the radial artery and the ulnar artery in patients with native upper arm FAV $(p<0.001)$, but after diagnostic testing, it was found that sensitivity was only $15 \%$ and specificity was $100 \%$.

Conclusion: There was a significant correlation between hand ischemia questionnaire and peak systolic velocity of the radial artery and ulnar artery in patients with upper arm native FAV, but due to the low sensitivity, the hand ischemia questionnaire cannot be used as an initial examination to detect steal syndrome in patients with no symptoms of hand ischemia.

Keywords: steal syndrome, Peak Systolic Velocity, Hand Ischemia Questionnaire. https://doi.org/10.36864/jinasvs.2020.1.001

*Correspondence: karundeng_billy@yahoo.com

M.D., Department of Surgery, Sam Ratulangi University Medical School/Prof. Dr. R. D. Kandou Hospital, Manado, North Sulawesi, Indonesia ${ }^{b}$ M.D., Ph.D., Vascular and Endovascular Division, Department of Surgery, Cipto Mangunkusumo Hospital - Faculty of Medicine, Universitas Indonesia, Jakarta, Indonesia

cM.D., M.T.I., Ph.D., Department of Community Medicine, Faculty of Medicine Universitas Indonesia, Jakarta, Indonesia

\section{INTRODUCTION}

Chronic kidney disease (CKD) is a global health problem, with an estimated prevalence of $8 \%$ to $16 \% .{ }^{1}$ Data from the Indonesian Renal Registry in 2017 recorded 77,892 patients actively undergoing hemodialysis procedures, with 30,831 of whom are new patients. ${ }^{2}$

One of the hemodialysis procedures that is often used is fistula arteriovenous (FAV). FAV in the upper arm uses the brachial artery as a feeding artery, consisting of brachiocephalic, brachiobasilic, and FAV, which uses loop graft as artificial vein draining and connected to the brachial artery. ${ }^{3}$ The diameter of the brachial artery, cephalic and basilica veins in the upper arm are greater than the diameter of the radial artery and cephalic vein in the wrist area, thereby increasing the maturity and patency rates of the upper arm FAV which is higher than the forearm FAV. ${ }^{4-8}$

One of the most feared complications of upper arm FAV is the occurrence of ischemic 
symptoms in the distal segment of the fistula, or more commonly referred to as arteriovenous access ischemic steal (AVAIS) or steal syndrome. ${ }^{9}$ The incidence of steal syndrome in upper arm access varies between $2 \%$ to $8 \%$, with several systematic review studies found that clinical symptoms of steal syndrome occur in $10-25 \%$ for upper arm fistulas that use cephalic or basilic veins and as much as 4.3-6\% for upper arm fistula that uses graft (arteriovenous graft/AVG). This is correlated with the more diameter, the more incidence of steal syndrome. Symptoms that appear can pain that initially only arises during hemodialysis, a cold sensation on the hands, and feels numb. In the advanced stages, the pain will be more painful and persist until ulcers and gangrene arise on the hands. 9,10

Hand Ischemia Questionnaire (HIQ) is a questionnaire to detect the initial symptoms of steal syndrome in hemodialysis patients with/without complaints of ischemia on the hands. ${ }^{11}$ There are questions that consist of subjective symptoms of stealing syndrome, which are cold sensation, pain, sensitivity, strength, and cramps. Also, objective examinations can be performed with Doppler ultrasound by measuring peak systolic velocity (PSV).

Research in Indonesia related to stealing syndrome is still very limited. This study aims to determine the correlation between HIQ and PSV measurement in patients with Brachial FAV.

\section{METHOD}

This research is a cross-sectional study conducted at the Polyclinic Division of the Vascular, Department of Surgery, Cipto Mangunkusumo National Hospital, Jakarta, in the period of MarchMay 2019.

The inclusion criteria in this study were all patients who underwent dialysis with brachiocephalic or brachiobasilic fistula access. Patients with cognitive impairment were excluded. HIQ assessment was carried out with guided interviews, and peak systolic velocity was assessed by Doppler ultrasound (iuStar100, United Imaging, Beijing, China) with a linear probe. The probe was placed longitudinally in the direction of the long axis of the arm and the radial artery and the ulnar artery, using $\mathrm{B}$-mode. After finding the radial artery, the long axis was assessed whether there was narrowing or not, and then the color mode was used to detect blood flow. The PW mode was used to assess PSV by placing the steer volume right in the middle of the lumen of the blood vessel and in the direction of the blood vessel with angle steer of $<60^{\circ}$. After that, using the automatic measurement method available in the "measure" menu, the PSV value was determined. Data were analyzed using SPSS version 24.0 for Windows ${ }^{\circledR}$.

\section{RESULTS}

In total, there were 80 samples in this study. Male patients were $37(46.2 \%)$, and women were $43(53.8 \%)$ with a mean age of 53 years. The most common type of fistula was 73 (91.2\%) brachiocephalic and 7 (8.7\%) brachiocephalic patients. The most common contributing factors for chronic kidney disease were hypertension in 70 $(87.5 \%)$ patients, diabetic nephropathy in $20(25 \%)$ patients, nephrotic syndrome in $8(10 \%)$ patients, and polycystic kidney disease in $2(2.5 \%)$ patients (table 1).

\begin{tabular}{ll}
\multicolumn{2}{c}{ Table 1. Patients characteristics. } \\
\hline Characteristics & $\mathbf{n}=\mathbf{8 0}$ \\
\hline Gender & 37 \\
Male & 43 \\
Female & $53(14-77)$ \\
Age, median (min-max) & \\
FAV type & 73 \\
BC sinistra & 7 \\
BC dextra & 27 (6-118) \\
Postoperative month, median (min-max) & \\
Causes of CKD & 20 \\
Diabetic Nephropathy & 70 \\
Hypertension & 2 \\
Polycystic Kidney Disease & 8 \\
Nephrotic Syndrome &
\end{tabular}

Based on the characteristics, the minimum value of HIQ was 0 and a maximum of 70 , with a median of 3 . In the FAV of the radial artery, the result of PSV was a minimum of $20 \mathrm{~cm} / \mathrm{s}, a$ maximum of $79 \mathrm{~cm} / \mathrm{s}$, with a median of $40 \mathrm{~cm} / \mathrm{s}$. In the ulnar, the results of PSV were a minimum of 16 $\mathrm{cm} / \mathrm{s}$, a maximum of $70 \mathrm{~cm} / \mathrm{s}$, with a median of 41 $\mathrm{cm} / \mathrm{s}$ (table 2).

Table 2. Characteristics of HIQ and PSV values of radial and ulnar

\begin{tabular}{lcccc}
\multicolumn{5}{c}{ artery } \\
\hline & Median & Min & Max & Range \\
\hline Cold & 0 & 0 & 19 & 19 \\
Pain & 0 & 0 & 17 & 17 \\
Sensibility & 0 & 0 & 18 & 18 \\
Motor & 0 & 0 & 18 & 18 \\
Cramp & 0 & 0 & 20 & 20 \\
Total HIQ & 3 & 0 & 70 & 70 \\
PSV radial a. AF & 40 & 20 & 79 & 59 \\
PSV ulnar a. AF & 41 & 16 & 70 & 54
\end{tabular}

HIQ: Hand Ischemic Questionnaire; AF: Arm Fistula

It shows that there was a correlation between HIQ and the PSV of the radial and the ulnar artery examined on the side of the fistula $(r=-0.7$, p <0.001) (table 3).

Table 3. Correlations between HIQ with PSV of radial and ulnar

\begin{tabular}{lcr}
\multicolumn{3}{c}{ artery } \\
\hline \multicolumn{2}{l}{ Correlation between HIQ and PSV } & \multicolumn{1}{c}{ Total HIQ } \\
\hline PSV radialis a. AF & $\mathrm{r}$ & $-.771^{* *}$ \\
& $\mathrm{p}$ & .000 \\
PSV ulnaris a. AF & $\mathrm{r}$ & $-.780^{* *}$ \\
& $\mathrm{p}$ & .000 \\
\hline
\end{tabular}

From the comparison table of HIQ examination and radial arterial PSV, using cut-off below and above $40 \mathrm{~cm} / \mathrm{s}$, it was found that in PSV results of $<40,34$ patients who were categorized as normal and normal variations and only 6 patients were suggestive for steal syndrome based on HIQ Score. On the results of the PSV examination $\geq 40$ $\mathrm{cm} / \mathrm{s}$, there were 40 patients in the normal category and normal variations, and there were no patients in the category of suggestive steal syndrome (table 4). 
Table 4. Comparison of HIQ and PSV results of radial artery above and below 40 .

\begin{tabular}{|c|c|c|c|c|c|}
\hline & & \multicolumn{4}{|c|}{ PSV radial artery } \\
\hline & & \multicolumn{2}{|c|}{$<40$} & \multicolumn{2}{|c|}{$\geq 40$} \\
\hline & & $n$ & $\%$ & $\mathbf{n}$ & $\%$ \\
\hline \multirow[t]{2}{*}{ Cold } & normal & 18 & $31.0 \%$ & 40 & $69.0 \%$ \\
\hline & abnormal & 22 & $100.0 \%$ & 0 & $0.0 \%$ \\
\hline \multirow[t]{2}{*}{ Pain } & normal & 29 & $42.0 \%$ & 40 & $58.0 \%$ \\
\hline & abnormal & 11 & $100.0 \%$ & 0 & $0.0 \%$ \\
\hline \multirow[t]{2}{*}{ Sensibility } & normal & 24 & $37.5 \%$ & 40 & $62.5 \%$ \\
\hline & abnormal & 16 & $100.0 \%$ & 0 & $0.0 \%$ \\
\hline \multirow[t]{2}{*}{ Motor } & normal & 24 & $37.5 \%$ & 40 & $62.5 \%$ \\
\hline & abnormal & 16 & $100.0 \%$ & 0 & $0.0 \%$ \\
\hline \multirow[t]{2}{*}{ Cramps } & normal & 25 & $38.5 \%$ & 40 & $61.5 \%$ \\
\hline & abnormal & 15 & $100.0 \%$ & 0 & $0.0 \%$ \\
\hline \multirow[t]{6}{*}{ HIQ } & normal & 0 & $0.0 \%$ & 40 & $100.0 \%$ \\
\hline & normal variation & 34 & $100.0 \%$ & 0 & $0.0 \%$ \\
\hline & suggestive steal syndrome & 6 & $100.0 \%$ & 0 & $0.0 \%$ \\
\hline & & \multicolumn{4}{|c|}{ PSV radial artery } \\
\hline & & \multicolumn{2}{|c|}{$<40$} & \multicolumn{2}{|c|}{$\geq 40$} \\
\hline & & $\mathrm{n}$ & $\%$ & $\mathbf{n}$ & $\%$ \\
\hline \multirow[t]{2}{*}{ Cold } & normal & 18 & $31.0 \%$ & 40 & $69.0 \%$ \\
\hline & abnormal & 21 & $95.5 \%$ & 1 & $4.5 \%$ \\
\hline \multirow[t]{2}{*}{ Pain } & normal & 28 & $40.6 \%$ & 41 & $59.4 \%$ \\
\hline & abnormal & 11 & $100.0 \%$ & 0 & $0.0 \%$ \\
\hline \multirow[t]{2}{*}{ Sensibility } & normal & 23 & $35.9 \%$ & 41 & $64.1 \%$ \\
\hline & abnormal & 16 & $100.0 \%$ & 0 & $0.0 \%$ \\
\hline \multirow[t]{2}{*}{ Motor } & normal & 23 & $35.9 \%$ & 41 & $64.1 \%$ \\
\hline & abnormal & 16 & $100.0 \%$ & 0 & $0.0 \%$ \\
\hline \multirow[t]{2}{*}{ Cramps } & normal & 24 & $36.9 \%$ & 41 & $63.1 \%$ \\
\hline & abnormal & 15 & $100.0 \%$ & 0 & $0.0 \%$ \\
\hline \multirow[t]{3}{*}{ HIQ } & normal & 0 & $0.0 \%$ & 41 & $100.0 \%$ \\
\hline & normal variation & 33 & $100 \%$ & 0 & $0.0 \%$ \\
\hline & suggestive steal syndrome & 6 & $100.0 \%$ & 0 & $0.0 \%$ \\
\hline
\end{tabular}

From the comparison table of HIQ examination results with PSV of the ulnar artery, using a cut-off below and above $40 \mathrm{~cm} / \mathrm{s}$, it was found that on PSV examination of $<40,33$ patients who were categorized as normal and normal variations and 6 patients were suggestive for steal syndrome based on HIQ score. On the results of the PSV examination of $\geq 40 \mathrm{~cm} / \mathrm{s}$, there were 41 patients in the normal category and normal variations, and there were no patients in the category of suggestive for steal syndrome (table 5).
PSV value of radial and ulnar artery using a cut-off value of $<40 \mathrm{~cm} / \mathrm{s}$. The sensitivity value was $15 \%$, and the specificity value was $100 \%$ for the diagnostic test results between the HIQ score and the radial artery PSV, and diagnostic accuracy of $57.5 \%$. From the diagnostic test results between the HIQ score and the ulnar artery PSV using the same cut-off value obtained a sensitivity value of $15.38 \%$ and a specificity value of $100 \%$, and a diagnostic accuracy of $58.75 \%$. This can be interpreted that if HIQ scores $\geq 50$ and PSV scores are obtained (tables

Table 6. Diagnosis Test between HIQ $(<50$ and $>50)$ against radial arterial PSV

\begin{tabular}{|c|c|c|c|c|}
\hline \multicolumn{5}{|c|}{ PSV radial artery } \\
\hline & & $<40$ & $\geq 40$ & Total \\
\hline \multirow[t]{3}{*}{ HIQ } & $\geq 50$ & 6 & 0 & 6 \\
\hline & $<50$ & 34 & 40 & 74 \\
\hline & & 40 & 40 & 80 \\
\hline \multicolumn{2}{|c|}{ Parameter } & Estimate & Lower - Upper 95\% Cls & Method \\
\hline \multicolumn{2}{|c|}{ Sensitivity } & $15 \%$ & $\left(7.061,29.07^{1}\right)$ & Wilson Score \\
\hline \multicolumn{2}{|c|}{ Specificity } & $100 \%$ & $\left(91.24,100^{1}\right)$ & Wilson Score \\
\hline \multicolumn{2}{|c|}{ Positive Predictive Value } & $100 \%$ & $\left(60.97,100^{1}\right)$ & Wilson Score \\
\hline \multicolumn{2}{|c|}{ Negative Predictive Value } & $54.05 \%$ & $\left(42.78,64.93^{1}\right)$ & Wilson Score \\
\hline \multicolumn{2}{|c|}{ Diagnostic Accuracy } & $57.5 \%$ & $\left(46.57,67.74^{1}\right)$ & Wilson Score \\
\hline
\end{tabular}


Table 7. Diagnostic tests between $\mathrm{HIQ}(<50$ and $>50)$ against PSV of the ulnar artery

\begin{tabular}{|c|c|c|c|c|}
\hline \multicolumn{5}{|c|}{ PSV A. ulnaris } \\
\hline \multirow{4}{*}{ HIQ } & & $<40$ & $\geq 40$ & Total \\
\hline & $\geq 50$ & 6 & 0 & 74 \\
\hline & $<50$ & 33 & 41 & 6 \\
\hline & & 39 & 41 & 80 \\
\hline \multicolumn{2}{|c|}{ Parameter } & Estimate & Lower - Upper $95 \%$ Cls & Method \\
\hline \multirow{2}{*}{\multicolumn{2}{|c|}{ ity }} & $15.38 \%$ & $\left(7.247,29.73^{1}\right)$ & Wilson Score \\
\hline & & $100 \%$ & $\left(91.43,100^{1}\right)$ & Wilson Score \\
\hline \multicolumn{2}{|c|}{ Predictive Value } & $100 \%$ & $\left(60.97,100^{1}\right)$ & Wilson Score \\
\hline \multicolumn{2}{|c|}{ e Predictive Value } & $55.41 \%$ & $\left(44.09,66.18^{1}\right)$ & Wilson Score \\
\hline \multicolumn{2}{|c|}{ tic Accuracy } & $58.75 \%$ & $\left(47.8,68.89^{1}\right)$ & Wilson Score \\
\hline
\end{tabular}

\section{DISCUSSION}

Based on the data obtained from the total score of the Hand Ischemia (HIQ) questionnaire, the minimum value was 0 , and the maximum value was 70 , with a median value of 3 . This finding was much lower when compared to previous studies conducted by Roel et al. ${ }^{11}$ in patients who already have symptoms related to Steal syndrome, HIQ scores were a median of 275 , a minimum value of 200 , and a maximum value of 311 . However, in the population of patients undergoing hemodialysis without any symptoms associated with steal syndrome, the results were similar to the minimum value of 0 , the maximum value of 41.5 , and the median value of 13.5. Compared with previous studies, the value of the HIQ score in patients without initial symptoms suspected of being related to Steal syndrome would be lower than for symptomatic patients.

One of the challenges was filling out the questionnaire. Of the five-question points on the HIQ questionnaire, the most difficult to understand by patients was the question about reduced motor strength. Patients with FAV automatically reduce the use of the arm with FAV for physical activity, so when asked if there was a reduction/weakness in strength motor related to the symptoms of steal syndrome, the patient could misinterpreted by the strength of the FAV arm muscles that were not used for physical activity. Furthermore, after examination of the HIQ score, all patients were examined to measure the value of the PSV of the radial and ulnar arteries of the side of the fistula by using a doppler ultrasound. From the results of this examination, it was obtained the characteristics of the radial artery arm fistula with a median value of 40 , a minimum value of 20 , and a maximum of 79 . For ulnar artery arm fistula, the results were a median value of 41 , a minimum value of 16 , and a maximum of 70 . The value obtained was almost similar to the study by Roel et al. ${ }^{11}$, with a median PSV value of the radial and ulnar arteries ranging from $40-43 \mathrm{~cm} / \mathrm{s}$. There was no significant difference between PSV of the radial and ulnar, in patients with a high HIQ score> 50 with a lower PSV value of $<40 \mathrm{~cm} / \mathrm{s}$ compared to patients with a low HIQ score less than 50 .

When a correlation test was performed between the total score of the HIQ questionnaire with radial and ulnar PSV scores, there was a strong and significant correlation $(r>-0.7 p<0.001)$. These results were consistent with the initial hypothesis in this study, with the higher HIQ questionnaire scores, the lower PSV values will be.

The sensitivity value obtained on the HIQ score against PSV in this study was found to be low due to the HIQ clinically is still said to be normal and normal variations from the score of $0-49$, while PSV values were at $<40 \mathrm{~cm} / \mathrm{s}$. On the other hand, the specificity value obtained was very high, because when HIQ clinical values were said to be suggestive of steal syndrome (score $\geq 50$ ), all PSV values of the radial and ulnar artery were obtained $<40 \mathrm{~cm} / \mathrm{s}$.

Based on this study, it can be said that the HIQ questionnaire cannot be used as a tool for early detection of stealing syndrome in a population of hemodialysis patients with upper arm FAV without ischemic complaints at hand. However, in patients who already have ischemic complaints, this questionnaire can be used because it has high specificity. This also has been proven in several previous studies ${ }^{9-11 .}$

\section{CONCLUSION}

There was a significant correlation between HIQ scores and PSV of radial and ulnar arteries in patients who have undergone hemodialysis using upper arm native fistula to detect symptoms of steal syndrome. The sensitivity of the HIQ diagnostic test was very poor, but it has excellent specificity to diagnose steal syndrome in patients with a complaint of ischaemic hand.

\section{ACKNOWLEDGMENTS}

The author states the original work, and there is no conflict of interest in doing this research.

\section{ORCID ID OF AUTHORS}

Billy Stephanus Karundeng

https://orcid.org/0000-0001-9049-0856

\section{Akhmadu Muradi}

https://orcid.org/0000-0003-0165-9045

Aria Kekalih

https://orcid.org/0000-0001-7811-097X 


\section{REFERENCES}

1. Jha V, Garcia-Garcia G, Iseki K, Li Z, Naicker S, Plattner B, et al. Chronic kidney disease: global dimension and perspectives. Lancet (London, England). 2013 Jul 20; 382(9888):260-72.

2. $8^{\text {th }}$ Report of Indonesian Renal Registry pdf. Indonesia. 2015.

3. National Kidney Foundation. KDOQI Clinical Practice Guidelines for Diabetes and CKD: 2012 update. Am J Kidney Dis. 2012;60(5):880-886.

4. Masengu A, McDaid J, Maxwell AP, Hanko JB. Preoperative radial artery volume flow is predictive of arteriovenous fistula outcomes. J Vasc Surg. 2016 Feb;63(2):429-35.

5. Lannery SL, Ihnat DM, Goshima KR, Mills JL. Veins diameter is the major predictor of fistula maturation. J Vasc Surg. 2009;49:1499-504.

6. Weale AR, Bevis P, Neary WD, Boyes S, Morgan JD, Lear PA, Mitchell DC. Radiocephalic and brachiocephalic arteriovenous fistula outcomes in the elderly. J Vasc Surgery. 2008;47:144-50.

7. Kim JJ, Gifford E, Nguyen V, Kaji AH, Chisum P. Increased use of brachiocephalic arteriovenous fistulas improves functional primary patency. J Vasc Surg. 2015;62:442-7

8. Zamboli P, Fiorini F, D'amelio A, Fatuzzo P. Color Doppler ultrasound and arteriovenous fistulas for hemodialysis. J Ultrasound. 2014;17:253-263.

9. Tordoir JH, Dammers R, van der Sande FM. Upper extremity ischemia and hemodialysis vascular access. Eur J Vasc Endovasc Surg. 2004;27(1):1-5.

10. Van Hoek F, Scheltinga MR, Kouwenberg I, Moret KE, Beerenhout CH, Tordoir JH. Steal in hemodialysis patients depends on type of vascular access. Eur J Vasc Endovasc Surg. 2006;32(6):710-7.

11. Roel HD, Tordoir JH, Scheltinga MR. Blood flow dynamics in patients with hemodialysis access-induced hand ischemia. J Vasc Surg. 2013;58:446-51. 